\title{
Pluvial flooding: hazard mapping and derivation of impact indicators
}

\author{
Axel Sauer ${ }^{1}$, Reinhard Schinke ${ }^{1}$, Regine Ortlepp ${ }^{1, a}$, Maria Papathoma-Köhle ${ }^{2}$ and Sven Fuchs ${ }^{2}$ \\ ${ }^{1}$ Leibniz Institute of Ecological Urban and Regional Development (IOER), 01217 Dresden, Germany \\ ${ }^{2}$ Institute of Mountain Risk Engineering (IAN), University of Natural Resources and Life Sciences, 1190 Vienna, Austria
}

\begin{abstract}
Climate change is likely to cause a change in frequency and intensity of convective thunderstorms and associated heavy precipitation. Typical consequences of such events are a rapid generation of surface runoff with high flow velocities in hilly and mountainous areas as well as the unexpected and abrupt occurrence of inundation in areas currently not known as flood-prone. The mapping of such pluvial flash flood events is still a developing field especially with regard to the post-processing of raw hydrodynamic model output data. Moreover, challenges include the derivation of indicators needed for quantification and visualisation of the impact dynamics on elements at risk such as buildings and infrastructures. This is important to support the understanding of vulnerabilities including uncertainties as well as to ensure a targeted interpretation of possible consequences and planning of mitigation measures. We present a three-step approach which includes (i) the calculation of surface runoff dynamics with a 2D hydrodynamic model, (ii) the derivation of impact indicators based on the modelling results as well as (iii) the presentation and mapping of key indicators in innovative hazard maps and diagrams.
\end{abstract}

\section{Motivation}

Convective thunderstorms and heavy precipitation are one of the main reasons of (pluvial) floods in small catchments characterised by steep slopes in hilly and mountainous terrains. Such events are typically associated with rapid onset and high flow velocities. Therefore, these pluvial floods are closely related to flash floods, one of the most significant natural hazards in the world (Gaume et al. 2009).

The temporal and spatial occurrence of pluvial and flash floods is hard to predict because of the small-scale variation of associated triggering weather events (e.g. Hofmann \& Schüttrumpf 2019). Compared to river flooding, they are characterised by some specific aspects that reflect on their impacts, consequences and associated risk, as well as on the resulting actions and measures taken to minimise negative effects.

Pluvial and flash floods are mainly caused by individual cells of convective thunderstorms and the flood event occurs within minutes and lasts up to a few hours limiting the available time for warning and mitigation.

Pluvial flooding occurs when rainfall intensity exceeds the infiltration capacity of the soil or the soil is already saturated; the resulting surface runoff fills up depressions and flows through the exposed area on its way to the next watercourse (Archer \& Fowler 2018, Borga et al. 2014). Therefore, the affected area is largely limited to the area of the rainfall source (thunderstorm cell) with an extent of a few square kilometres. However, the flood wave in the watercourses generated by such events can travel into areas distant from the thunderstorm event (typically in Mediterranean, mountainous and desert environments).

There is a general trend to manage flood hazards and risks not only at the source and pathway but also on the receptor side, a strategy commonly known as integrated flood risk management (ISO 2009). Facing flash floods, active flood protection and mitigation measures are supplemented by passive measures such as hazard mapping, mainly because of a decoupling between hazard source and hazard impact. As a consequence of this decoupling, traditional cost-benefit analysis for mitigation measures and environmental impact analysis remains fragmented.

In addition, there are challenges (i) to precisely forecast the temporal and spatial occurrence of precipitation events, (ii) to assess information about occurrence probabilities (cf. Acosta-Coll et al. 2018), and (iii) to derive appropriate measures of long-term preparedness. The latter is of special importance due to the limited time of issuing warnings and taking necessary mitigation action.

In our contribution, we focus on the use of indicators to improve the understanding of the interaction between hazard processes (pluvial flash floods) and impacts on the built environment, and to enable decision-makers to develop necessary action strategies on a local level and object-specific scale. In addition, the results should be

${ }^{\text {a }}$ Corresponding author: a.sauer@ioer.de

DOI 10.3311/FLOODRisk2020.9.9 
used to identify previously unrecognised hazard and risk areas. Therefore, we approach the challenges from the hazard side in order to open up the possibility of screening procedures for a variety of different investigation areas.

The indicators themselves are defined as variables representing the characteristic or the quality of a system, such as the hazard-building interface (Birkmann 2006; Fuchs et al. 2018). They are designed to recognize specific aspects, to cluster features, or to reduce the amount of required data (Wang 2015, Papathoma-Köhle 2017). The indicators used here are intended to get a quick overview providing dedicated information about the interface between hazard and the flood exposed objects. However, it is necessary to have a clear understanding of the specific (multi-)impact situation at or close to the relevant objects exposed both with a high spatial and temporal differentiation in order to select appropriate preparedness and mitigation measures at the object scale (e.g. buildings, roads, etc.) (Mazzorana et al. 2014, Sturm et al. 2018). This is a decisive basis to provide object-specific additional information to homeowners and public authorities (municipalities, energy providers, etc.) in order to mitigate the impacts on buildings and infrastructure (Meyer et al. 2012, Attems et al. 2020).

We focus on the Federal Republic of Germany, where, currently, hazard maps communicating threats resulting from heavy rain events are hardly available. Regarding their content, they often show only reduced information such as flow accumulation or flow pathways independent from an event, event-based inundated areas with classified maximum water levels and - rarely maximum flow velocities. Such information, however, is not sufficient to evaluate the different impacts on elements at risk - especially buildings and their surroundings - during a pluvial flood event (Simões et al. 2015). In contrast, there are open questions significant to holistic impact assessment in order to improve the derivation of vulnerability and resilience. They are related to: (i) the time assets are exposed to certain water levels and flow velocities (causing water or moisture damage and structural damage, e.g. by erosion beneath the foundation), (ii) the time until a certain water level is reached, the potential for erosion and sediment deposition, and (iii) the flow directions and angles a water body is approaching an element at risk, including floating logs and debris.

To bridge this gap, we present a hazard mapping method which additionally includes specific information based on indicators easily to interpret by multiple stakeholders so that meaningful maps and diagrams can be produced.

The target group we are aiming at are local stakeholders and citizens that are in need of precise and easy to understand impact indicators.

\section{Method}

The method consists of a three-step approach including (i) the calculation of surface runoff dynamics with a 2D hydrodynamic model, (ii) the derivation of simple and complex impact indicators based on the modelling results as well as (iii) the mapping of key indicators in innovative hazard maps and diagrams.

In this way we use the differentiation of simple and complex impact indicators to describe (i) simple indicators based on one output parameter of the hydraulic model simply aggregated over time (e.g. maximum water level) and (ii) indicators based on a threshold criteria selection and constrained by an additional parameter (e.g. duration of flow velocities $>\mathrm{x}$ in areas with a water level $>\mathrm{y})$.

\subsection{Hydrodynamic modelling}

Process-based hydrodynamic models are essential tools to simulate the flow of water during pluvial flood events with a high spatial and temporal resolution of water levels and flow velocities and directions.

Here, the hazard dynamics are simulated with the "high-performance integrated modelling system" (HiPIMS, Smith \& Liang 2013; Smith et al. 2015). The model provides a numerical 2D implementation of the fully dynamic shallow water equation (SWE) based on a finite volume approach. The model has been successfully validated for numerous artificial test cases as well as for event-based examples (ibid., Liang \& Smith 2014, Liang et al. 2016). The model can be run on graphics processing units (GPUs) leading to a speedup of simulation runs on the GPU of 8 to 30 times depending on the simulation domain and the numerical precision. It enables multiple simulations of different alternatives in a relatively short time to compensate the limited knowledge regarding the rainfall event, as well as catchment/surface characteristics, e.g. blocked culverts (Sauer et al. 2018, 2019).

Driving input parameters for the HiPIMS model are precipitation time series as global constant intensity "block" rain, observed/synthetic time series for the whole domain, observations from rain gauges/weather stations as well as time/space varying raster datasets/radar rain.

The model surface for the flow calculations is represented as a regular Cartesian grid which can be parameterised based on digital terrain models (DTMs) that typically need to be further detailed with additional height and geometry information of hydraulically relevant structures such as buildings, culverts, ditches, flood defence walls, etc.

A further necessary parameter relates to the hydraulic roughness of the surface in terms of the GaucklerManning-Strickler (GMS) coefficient. This parameter can be set as a global, space-invariant value for the whole model domain or as a spatially varying raster dataset representing different values for land uses or surface types, respectively.

Resolution/extent of the simulation domain is only limited by the hardware, e.g. the GPU memory.

The model results are in grid form (georeferenced raster files) with a freely selectable output time step down to 1 second. Output parameters are water level, elevation of the water surface as well as the horizontal and vertical 
component of the flow vector. Flow direction and resulting flow velocity can further be calculated.

The derivation of interpretable impact indicators from this raw model outputs and the coupling of these indicators to receptors is presented in section 2.3.

\subsection{Test areas, data, and data processing}

Implementation and testing of our method was carried out in two catchments in Saxony (Germany) which have suffered from severe pluvial flash flood events in the past. One catchment is located in the urban-rural interface at the edge of Meißen, a city in the north of Dresden (abbreviated MEI). The other area is situated around Spitzkunnersdorf, a village in the east part of Saxony, close to the border to the Czech Republic and the Republic of Poland (abbreviated SPK). MEI covers an area of approx. $6.2 \mathrm{~km}^{2}$ and SPK of $7.3 \mathrm{~km}^{2}$.

For both areas, comprehensive photo documentation provides insights during and/or after the respective pluvial flood events. This was used for the validation of hydrodynamic modelling results as well as for the comparison of observed impacts and damage pattern with the indicator maps.

The input data for the hydrodynamic model described in section 2.1 were prepared as follows:

Rainfall: Different datasets have been used: (i) gridded radar rainfall data for the major events in the two catchments. The data are based on the YW radar product of the German National Meteorological Service (DWD) with a spatial resolution of 250 meters and a temporal resolution of five minutes (Winterrath et al. 2018), (ii) artificial events of $60 \mathrm{~min}$ duration and return periods of 10,30 and 100 years based on DWD's precipitation statistics KOSTRA for heavy rain events and the EULER II method to generate synthetic storms with 5-min intervals and (iii) a $60 \mathrm{~min} 54 \mathrm{~mm} / \mathrm{h}$ block rain (abbrev. "block 60_54”).

DTM: The surface model is based on a DTM of the Saxon Surveying Agency (GeoSN) with 2-meter resolution (GeoSN 2020a) which does not include buildings and vegetation. To take into account the role of buildings the DTM has been enriched with building information using (i) vector-to-raster conversion of the building outlines (GeoSN 2020b) and alignment to the DTM raster regarding resolution and cell coordinates, (ii) setting the values in the buildings raster to a value of 10 meters, and (iii) combination of both rasters with an addition operation (DTM raster + buildings raster).

$G M S$ : The GMS hydraulic surface roughness has been set for MEI to a global value of 0.04 (= prefix 0.04 in descriptions), which is a medium roughness applicable to moderately vegetated and built-up areas (e.g. used by Smith et al. 2015 and Liang et al. 2016). For SPK this global constant as well as a spatially distributed set of values based on land use types have been used (only for the 100 year EULER rain: abbrev. "map eu2_100").

The output data comprising of single raster files for each of the four variables and time steps was bundled in a HDF5 file per simulation variant for further analysis steps. The dimensions of the resulting "data cubes" in time steps (z), columns and rows are shown in table 1 . The disk storage space of the files is 1.1 and $1.8 \mathrm{~GB}$ per simulation alternative.

Table 1. Model dimensions of the test areas.

\begin{tabular}{|c|c|c|c|c|}
\hline $\begin{array}{c}\text { Area } \\
\text { abbrev. }\end{array}$ & $\begin{array}{c}\text { Time } \\
\text { steps }\end{array}$ & Columns & Rows & Cells \\
\hline MEI & 120 & 1434 & 1124 & 1.6 Mio. \\
\hline SPK & 120 & 1423 & 1318 & 1.9 Mio. \\
\hline
\end{tabular}

All analysis steps were carried out with $\mathrm{R}$ and the packages "hdf5r", "sf" and "ggplot2". Map generation was done with QGIS 3.6.0 and R ("ggplot2", "metR").

\subsection{Impact indicators}

The impact and consequences of the flood water depend on receptors (e.g. buildings) and the damage processes taking place. While some indicators are receptor-specific others can be interpreted for different receptors. In this section, we describe the derivation of indicators (see table 2), possible interpretations and limitations. Firstly, the procedures for more common indicators are described and secondly, for complex and new indicators (see also Papathoma-Köhle et al. 2019).

Table 2. Indicators.

\begin{tabular}{|c|l|}
\hline Symbol & Name \\
\hline$h_{w . m a x}$ & Maximum water level \\
\hline$v_{f . m a x}$ & Maximum flow velocity \\
\hline$T_{h w, \text { crit }}$ & Duration of critical water level \\
\hline$t_{h w . c r i t}$ & Time to critical water level \\
\hline$T_{\text {vf.crit }}$ & Duration of critical flow velocities \\
\hline$\delta_{f}$ & Flow direction \\
\hline
\end{tabular}

Maximum water level $h_{w . m a x}$ and maximum flow velocity $\underline{\text { ff.max }}$

Both indicators characterise a basic analysis of floods using hydro-numeric modelling. The maximum water level $h_{\text {w.max }}$ during an event is derived by identifying the maximum value for each raster point along the time dimension. The resulting map shows a synoptic situation, as if these water levels would all have occurred at the same time. Especially when considering pluvial flood events in hilly areas, peak water levels commonly last only for a relatively short time. This indicator $h_{w \text { max }}$, however, does not provide information on the flood duration and on possible moisture penetration degree of building construction.

The maximum flow velocity $v_{\text {f.max }}$ is an indicator usually not shown in flood hazard maps. Its calculation and general interpretation is identical to the previous indicator. Simultaneously, the indicator $v_{f \cdot \max }$ provides no 
information on the duration of damaging processes such as the erosion of soils and sediments as well as on related undercutting processes weakening building structures such as foundations.

\section{Duration of critical water level $T_{h w, \text { crit }}$}

Its calculation is based on a selection of time steps per raster point where the value is above a threshold, e.g. defined by the entry level of a certain building, and a summation of these time steps to a total duration. This indicator provides information regarding different impacts on elements at risk such as (i) the duration a certain receptor is exposed to a critical water level $T_{h w . c r i t}$ allowing to roughly assess the inflow of water into a building, or (ii) the intensity of moisture penetration processes of building materials or (iii) the duration a road is blocked for certain types of vehicles based on their wading depth (e.g. set as critical level).

\section{$\underline{\text { Time to critical water level }} t_{h w . c r i t}$}

The indicator $t_{h w \text { max }}$ or $t_{h w . c r i t}$ provides information on how much time is available to undertake protection or evacuation measures or the time at which certain roads become blocked. The definition of a critical water level $h_{\text {w.crit }}$ is receptor specific and depends e.g. for buildings, on the existence of cellars/basements with openings at the ground level or other entry points.

The data analysis identifies for each cell the time difference between the first occurrence of $h_{w \text { max }}$ or $h_{w . c r i t}$ and the beginning of the event, leading to the duration (also known as "time to peak" if related to $h_{w \cdot \max }$ ). In case of synthetic storms, the beginning can clearly be defined by the time step when precipitation starts. In the case of observed events, the beginning may also be determined by a certain rainfall intensity or accumulated rainfall threshold.

\section{Duration of critical flow velocities $T_{v f, c r i t}$}

Similar to the preceding indicator, the critical flow velocity $v_{\text {f.crit }}$ is specific for certain receptors and impact processes, e.g. erosion of sediments, and the calculation rule is identical. With the indicator $T_{v f, c r i t}$, the intensity of bed, bank, and surface erosion can be interpreted, based on the analogy that the duration of a critical erosion situation correlates with the process intensity. Thresholds for the flow velocity characterising certain processes are often available. One example relates to erosion, transport, and deposition of sediments depending on their size/texture and flow velocity based on the well-known Hjulström curves (Hjulström 1935). Such receptor or process related threshold values could then be used to analyse the process intensity in terms of the duration of the defined process conditions, e.g. erosion of soils and sediments. Depending on the receptor, it is useful to avoid showing $v_{\text {fcrit }}$ for areas with very shallow water levels. This can be achieved by using a depth constraint during the calculation procedure.

It has to be mentioned that this indicator does not take into account material entering certain locations from upstream.

\section{Flow direction $\delta_{f}$}

The flow direction $\delta_{f}$, close to a receptor (e.g. building), provides information on how the structure is exposed to the forces of the flowing water. In combination with water level $h_{w}$ and flow velocities $v_{f}$, it allows to interpret the dynamic loads acting on the building envelope. The indicator $\delta_{f}$ shows a high variability over time, depending on the spatial distribution of the rainfall and the concentration and routing of the surface runoff.

\section{Linking indicators to receptors: buildings}

The indicators described above can be joined to exposed receptors like buildings with the help of spatial analysis techniques. This can be termed as a "virtual exposure analysis". Taken the receptor buildings as an example, the following processing steps have been carried out: (i) creating a buffer of 4 meters around every building outline, (ii) for each indicator: selecting of the raster cells within the buffer area, (iii) aggregation of the set of cells with the functions maximum, median and mean, (iv) joining of the resulting values as attribute information to each building. In our cases, the use of a buffer value was necessary to consider the effects of the orthogonal raster cell with the $2 \mathrm{~m}$ model resolution and geometric imperfections resulting from the transfer of the building polygon to the raster cells geometry.

In the following paragraphs, we present the results of the application of the methodology in Saxony showing how these indicators can be visualised using maps and diagrams.

\section{Results and discussion}

$\underline{\text { Indicators }} h_{w, \max } \underline{\text { and }}_{\boldsymbol{v}_{\text {, max }}{ }^{\mathrm{a}}}$

Reflecting the basis indicators, the provided maps should illustrate a very typical situation of pluvial floods with the water flow through the exposed area and later in the watercourse.

Figure 7 shows the indicator $h_{w, \max }$ assigned to the receptor "buildings" for the area SPK. Here the maximum pixel value of the $h_{w, \max }$ raster in the buffer area around the building has been visualised. The options "median of pixel values in buffer area" and "mean of pixel values in buffer area" have been joined as additional attribute information to the building geometries. The end-user can quickly identify the impact intensity for each building. Besides the buildings with high intensities located close to the watercourse, there are numerous buildings that are exposed to overland flow and ponding processes independent of the watercourse, what is the typical picture of a pluvial flood event.

The indicator $v_{f, \max }$ is displayed for the area SPK (what counts also for the following indicators) in Figure 3. Flow velocities $v_{f}<0.1 \mathrm{~m} / \mathrm{s}$ have been set as transparent. The maximum values of approx. $5 \mathrm{~m} / \mathrm{s}$ can be observed along the watercourse running from west to

\footnotetext{
${ }^{\text {a }}$ For better readability, the Figures 3-7 with the result maps are positioned at the end of the article.
} 
east through the village. Flow pathways coming from the agricultural areas surrounding the village and running into the built-up area are clearly visible. In some cases, the streets act as artificial flow pathways (e.g. the S139 in the eastern part or the street in the centre south of and parallel to the watercourse). Higher $v_{f}$ between 1 and 2 $\mathrm{m} / \mathrm{s}$ can also be observed close to buildings in the village. Usually, the interpretation of this indicator regarding potential damage is limited due to the synoptic nature of the indicator (maximum over all time steps) and the missing of information on how long vulnerable receptors such as buildings and street paving were exposed to the dynamic flow processes. Following the procedure outlined in section 2, however, in-depth information becomes available.

\section{Indicator $T_{v f, c r i t}$}

Figure 5 shows $T_{v f \text { crit }}$ for the erosion and transport of silty and sandy soils with more than $0.5 \mathrm{~m} / \mathrm{s}$. Figure 6 reflects the $T_{v f \text {,crit }}$ more than $1 \mathrm{~m} / \mathrm{s}$ associated with the erosion and transport of coarse sediments, e.g. gravel.

Both maps allow a detailed identification and differentiation of the threatened areas. Sources and routes of soil-laden surface runoff can be identified by visual comparison of the land use information in the background map (white is agricultural land) and the flow pathways. Several areas with intensive erosion or shear stress between 60 and 80 minutes on or close to streets and near buildings can be identified at the $>1 \mathrm{~m} / \mathrm{s}$-threshold map. Those streets for example are, depending on the paving material and its condition, likely to be damaged.

\section{Indicator $t_{h w . c r i t}$}

In our case studies we have defined $h_{w, \max }$ as threshold, see Figure 4 with the spatial distribution of the indicator $t_{h w, c r i t}$ for a $60 \mathrm{~min}$ precipitation event and a model runtime of 120 minutes. Water levels $<1 \mathrm{~cm}$ have been excluded. In the upper parts of the different subcatchments with their dendritic flow and inundation patterns $h_{w, \max }$ is reached after 20 to 30 minutes. In the northern and eastern parts of the village, the flood peak occurs in the range of 30 to 40 minutes. This pattern reflects the concentration of the surface runoff and the travelling of the flood wave. Compared to the other indicators the spatial variation takes place on a remarkably smaller scale where gradients are visible in a range of hundreds of meters compared e.g. to $v_{f}$ where the process intensity varies from cell to cell (here 2 meters).

For the area SPK and the given synthetic rainfall (comparable to the observed major event of the near past) it can be concluded that lead time is very short and, therefore, the time for temporary and ad-hoc measures is very limited. This situation calls for a strategy focussing on permanent measures such as property-level flood risk adaptation at the receptor side, which follows the principles of prevention and preparedness.

\section{$\underline{\text { Indicator } \delta_{f}}$}

The map design for the indicator $\delta_{\mathrm{f}}$ is shown in Figure 1. It is a combined visualisation showing $v_{f}$ additionally via the length of the flow arrows (the longer, the higher) as well as by an interpolated/smoothed colour coding on a cell basis. The arrows originate from the cell holding the information and point towards the direction of flow. There is currently no aggregation over the time dimension, hence, each visualisation shows a certain time step during the simulation requiring a look on every time step. Alternatively, such information for the whole simulation or event time can be animated. The flow directions $\delta_{\mathrm{f}}$ in Figure 1 show in some areas a remarkable variation over time. This becomes clear by comparing the upper and the lower map with a difference of 10 minutes between the two time steps. As shown in the middle and lower map, there is a more or less stable flow pattern observable, which might be aggregated over time by a mean or dominance over time operation

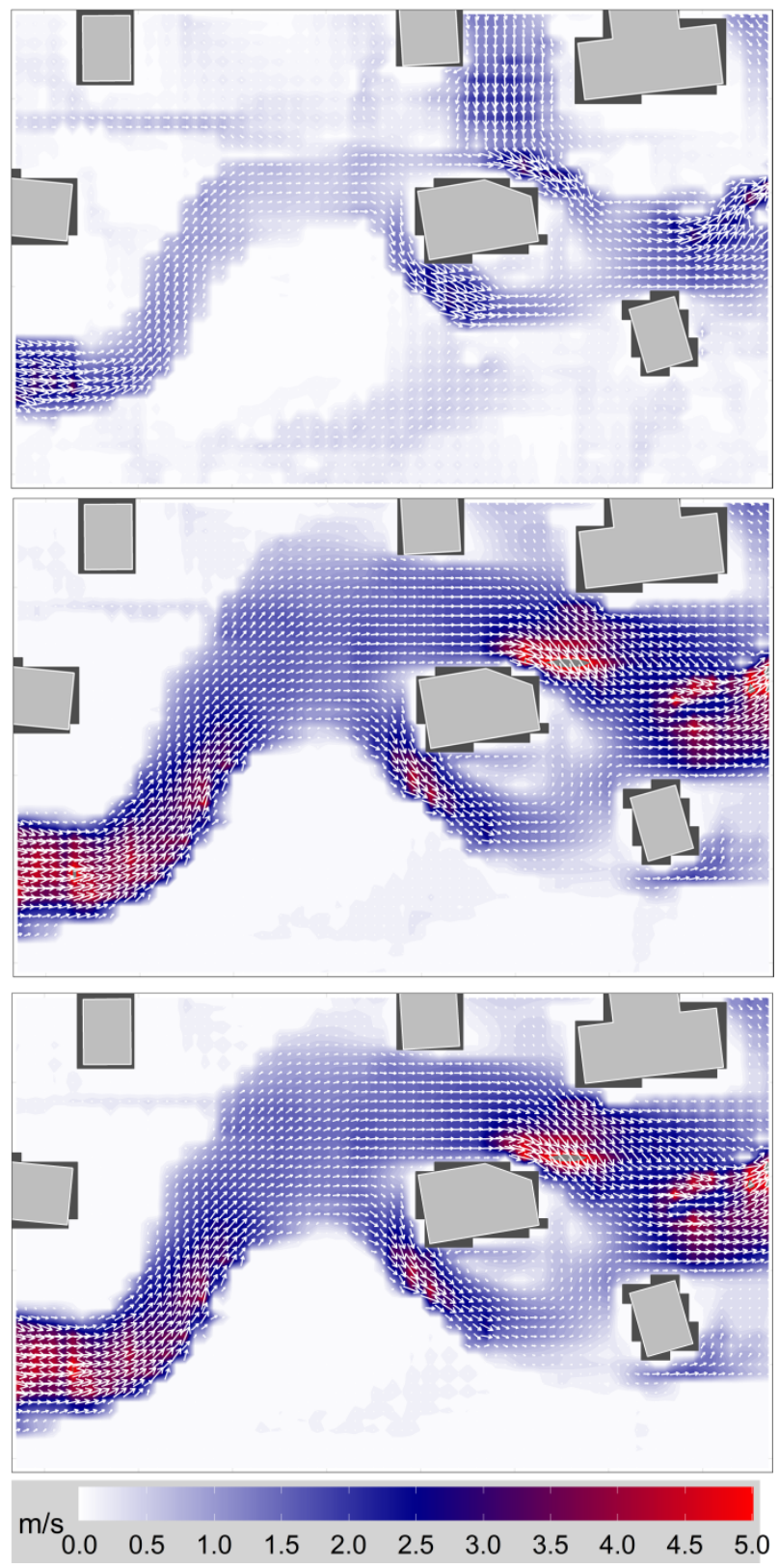

Figure 1. Combined visualisation of $\delta_{f}$ and $v_{f}$ via length and orientation of flow arrows and colour scheme for a $100 \times 50$ meter subset from area SPK and three time steps (from top to bottom: 20, 25, and 30 minutes). The event is a $60 \mathrm{~min} 1: 100$ years synthetic EULER II storm (alternative (a) in Figure 2). For the location of this subset see Figure 7. 
A further challenge is the automatic linking of the flow direction information to a receptor. The building in the centre of the map faces different flow situations during the event related to the different walls. At the moment, visual interpretation via the geographical location is recommended, while in the future, an automatic linking and aggregation for the different exterior wall elements via spatial buffering operations and aggregations of the selected cells should be tested.

\section{Need for diagrams}

Comparisons regarding the effects of different rainfall events and parameter settings can be carried out via visual comparisons of the indicator maps for alternatives (a) and (b) or by difference maps derived via a raster subtraction operation (alternative (a) minus (b)). Exemplary alternatives are shown in the legend of Figure 2 with a focus on different rainfall inputs.
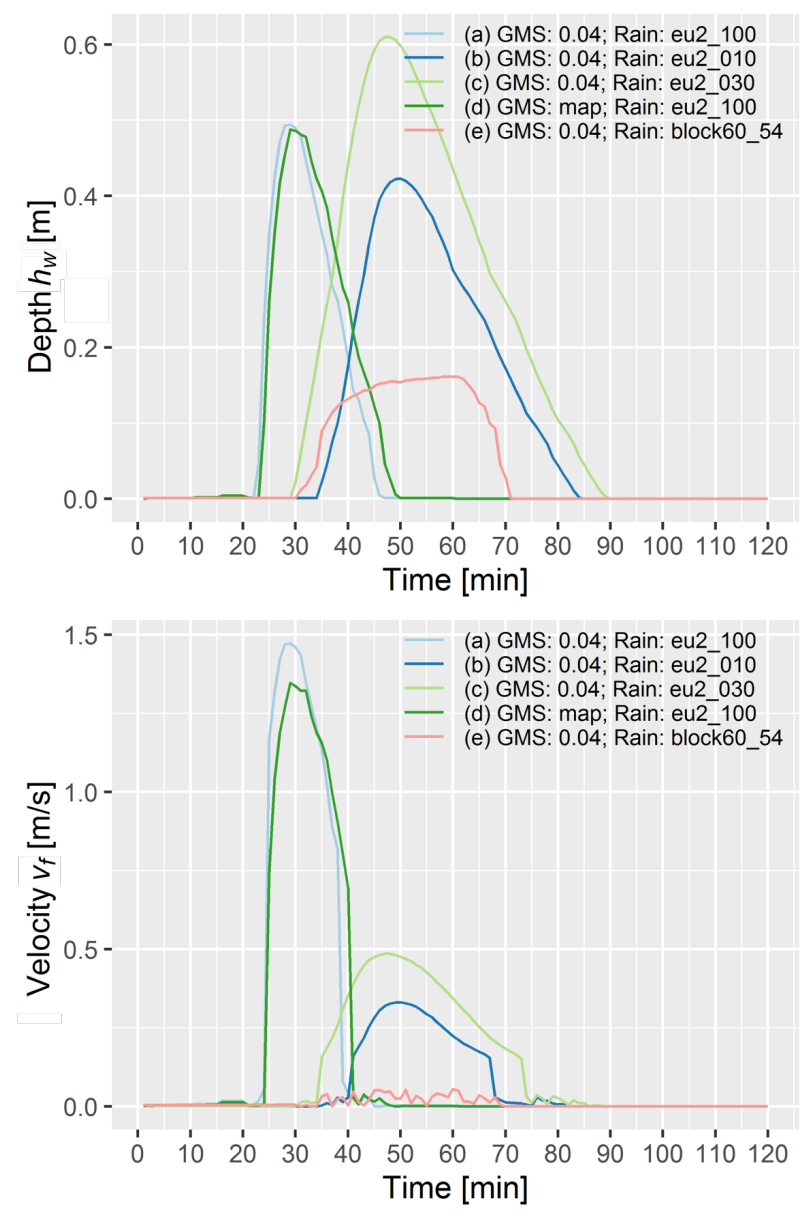

Figure 2. Diagrams of the time variable indicators $h_{w}$ (top) and $v_{f}$ (bottom) for a selected point and five different simulation alternatives. The location is close to the north-western corner of the building in the centre of Figure 1.

Both ways of visualising provide only limited information on the differences regarding the temporal dynamics and are challenging to interpret if more than two alternatives need to be compared as well as when certain points in the area of specific interest. This can be better addressed by diagrams for selected points showing the dynamics of an indicator over time combined for the different alternatives. Figure 2 gives an example for such diagrams, showing the development of $h_{w}$ and $v_{f}$ over time.

\section{Conclusions}

Hydrodynamic 2D models are essential tools for the process-based simulation of potential impacts during highly dynamic pluvial flood events. They are able to simulate different artificial or observed rainfall inputs allowing the analysis of the corresponding flow patterns resulting from rainfall events with different intensities in terms of volume and duration.

The outputs of the hydrodynamic models need to be provided with a temporal resolution adjusted to the dynamics of the event, typically in the range of minutes when dealing with short time, high intensity precipitation events.

Furthermore, indicators related to certain impacts such as $h_{w, \max }$ and $v_{f, \max }$ used in the past to describe the intensity of an event give only little information on possible effects. Since the duration of the load or impact situation are important factors regarding the extent of damage, these should be increasingly taken into account in risk modelling.

More complex indicators with a stronger focus on the time factor and, therefore, the duration of a certain impact situation provide valuable additional information needed to evaluate the potential adverse effects for a receptor. This information can be used as a basis to start with the conception and selection of specific mitigation measures as well as to prepare emergency plans to anticipate necessary actions.

The indicator information can be joined to selected receptors such as buildings and infrastructures with the help of spatial analysis techniques. Based on the different levels of the impact indicators, a receptor-specific screening of the individual exposure of each building is possible. An open task is the classification and rating of the individual as well as combined indicator values regarding the impacts for certain receptors, e.g. thresholds differentiating severity levels. With the help of such a rating it will be possible to identify buildings that are highly exposed.

To assess the resulting risk of these buildings, a vulnerability assessment e.g. using the Physical Vulnerability Index (PVI) (Papathoma-Köhle et al. 2019) is the next necessary step for an integrated risk assessment. In addition, the hazard modelling including the indicator analysis shown here, provide an essential basis for any damage and risk modelling. By using the synthetic damage model approach (Neubert et al. 2016, Schinke et al. 2012), it is possible to analyse the (economic) effects of any flood protection and mitigation measures including precautionary measures at the object level (Schinke et al. 2016). The achieved results are helpful to prioritise various action alternatives and support decision making processes.

As far as visualisation is concerned, the different spatial scales of the variation of the indicator variables require different map scales for visualisation, taking also 
into account the requirements of graphical representations needed to display them, e.g. the space occupied by the flow arrows at each cell centre. One solution would be to move from static map layouts to flexible and dynamic online mapping solutions.

Due to the process of integrating buildings in the DTM and the limitations of the raster geometry model (resolution, 90 degree angles), careful interpretation of the simulation results and indicator values is recommended considering local and object-specific information. Such information includes e.g. small elements such as garden walls, the height of the building entry/ground floor as well as the localisation and extent of potential entry points (cellar windows, doors, etc.). These data might be provided by "local experts" (inhabitants, homeowners, local public administration) to refine the model input data. To avoid misinterpretation of the indicator maps, a clear communication of the underlying assumptions and simplifications is necessary.

In summary, the presented three-step approach is particularly suitable for screening procedures to identify previously unrecognised pluvial flood hazard and risk areas. The far-reaching possibilities of an indicator-based analysis illustrated the easily interpretation of the resulting hazard and risk information as well as their reflection in meaningful maps and diagrams.

\section{Acknowledgement}

The presented work is part of different research projects. It includes results from "RAINMAN - Integrated Heavy Rain Risk Management" and "STRIMA II Saxon-Czech Flood Risk Management II" which are founded by the European Union (European Regional Development Fund, RAINMAN: Interreg CENTRAL EUROPE 2020; STRIMA II: Interreg VA „Ahoj sousede. Hallo Nachbar." 2017-2020). In addition, Maria Papathoma-Köhle and Sven Fuchs received funding from the Austrian Science Fund (FWF): V-519-N29 and P27400-NBL. The authors thank all funding agencies for their financial support.

\section{References}

1. Acosta-Coll, M., Ballester-Merelo, F., MartinezPeiro, M., De la Hoz-Franco, E. (2018). Real-time early warning system design for pluvial flash floods - A review. Sensors 18, 2255, 1-26.

2. Archer, D.R., Fowler, H.J. (2018). Characterising flash flood response to intense rainfall and impacts using historical information and gauged data in Britain. Journal of Flood Risk Management 11, 121133.

3. Attems, M.-S., Thaler, T., Genovese, E., Fuchs, S. (2020). Implementation of property level flood risk adaptation (PLFRA) measures: choices and decisions. WIREs Water 7(1), e1404.

4. Gaume, E., Bain, V., Bernardara, P., Newinger, O., Barbuc, M., Bateman, A., Blaškovičová, L., Blöschl, G., Borga, M., Dumitrescu, A., Daliakopoulos, I., Garcia, J., Irimescu, A., Kohnova, S., Koutroulis, A.,
Marchi, L., Matreata, S., Medina, V., Preciso, E., Sempere-Torres, D., Stancalie, G., Szolgay, J., Tsanis, I., Velasco, D., Viglione, A. (2009). A compilation of data on European flash floods. Journal of Hydrology 367(1-2), 70-78.

5. GeoSN: Staatsbetrieb Geobasisinformation und Vermessung Sachsen (2020a). DGM2 (=Digital Terrain Model 2-meter resolution). Online: https://www.

geodaten.sachsen.de/downloadbereich-dgm24164.html

6. GeoSN: Staatsbetrieb Geobasisinformation und Vermessung Sachsen (2020b). Hausumringe (=building footprint). Online: https://www.geodaten.sachsen.de/ downloadbereich-hausumringe-4174.html

7. Hjulstöm, F. (1935). Studies of the morphological activity of rivers as illustrated by the river Fyris. Bulletin of the Geological Institute 25, 221-527.

8. Hofmann, J., Schüttrumpf, H. (2019). Risk-based early warning system for pluvial flash floods: Approaches and foundations. Geosciences 9, 127, 122.

9. ISO (2009). ISO 31000:2009, Risk management Principles and guidelines. Geneva.

10. Liang, Q., Smith, L.S. (2014). A high-performance integrated hydrodynamic modelling system for urban flood inundation. Journal of Hydroinformatics 17(4), 518-533.

11. Liang, Q., Xia, X., Hou, J. (2016). Catchment-scale high-resolution flash flood simulation using the GPU-based technology. Procedia Engineering 154, 975-981.

12. Mazzorana, B., Simoni, S., Scherer, C., Gems, B., Fuchs, S., Keiler, M. (2014). A physical approach on flood risk vulnerability of buildings. Hydrology and Earth System Sciences 18(9), 3817-3836.

13. Meyer, V., Kuhlicke, C., Luther, J., Fuchs, S., Priest, S., Dorner, W., Serrhini, K., Pardoe, J., McCarthy, S., Seidel, J., Scheuer, S., Palka, G., Unnerstall, H., Viavatenne C. (2012). Recommendations for the user-specific enhancement of flood maps. Natural Hazards and Earth System Sciences 12(5), 17011716.

14. Neubert, M., Naumann, T., Hennersdorf, J., Nikolowski, J. (2016). The Geographic Information System-based flood damage simulation model HOWAD. Journal of Flood Risk Management 9(1), 36-49.

15. Papathoma-Köhle, M., Gems, B., Sturm, M., Fuchs, S. (2017). Matrices, curves and indicators: A review of approaches to assess physical vulnerability to debris flows. Earth-Sciences Reviews 171, 272-288.

16. Papathoma-Köhle, M., Schlögl, M., Fuchs, S. (2019). Vulnerability indicators for natural hazards: an innovative selection and weighting approach. Scientific Reports 9, 15026.

17. Sauer, A.; Olfert, A.; Körte, L.; Ortlepp, R. (2018). An uncertain business: Mapping flood hazards caused by heavy rain. In: Extended Abstracts of the 16th International Probabilistic Workshop 2018 in Vienna. Beton- und Stahlbetonbau 113, S2, 95-100. 
18. Sauer, A; Körte, L; Ortlepp, R. (2019) Parameter uncertainties in flood hazard analysis of heavy rain events. In: Yurchenko, D.; Proske, D. (eds) Proceedings of the 17th International Probabilistic Workshop, 11.-13. September 2019, Edinburgh, UK, 37-42.

19. Schinke, R.; Neubert, M.; Hennersdorf, J.; Stodolny, U.; Sommer, T.; Naumann, T. (2012). Damage estimation of subterranean building constructions due to groundwater inundation - the GIS-based model approach GRUWAD. Natural Hazards and Earth System Sciences. 12(9), 2865-2877.

20. Schinke, R.; Kaidel, A.; Golz, S.; Naumann, T.; López-Gutiérrez, J.S.; Garvin, S. (2016). Analysing the Effects of Flood-Resilience Technologies in Urban Areas Using a Synthetic Model Approach). ISPRS International Journal of Geoinformation 2016, 5, 202

21. Smith, L.S., Liang, Q. (2013). Towards a generalised GPU/CPU shallow-flow modelling tool. Computers \& Fluids 88, 334-343.
22. Smith, L.S., Liang, Q., Quinn, P.F. (2015). Towards a hydrodynamic modelling framework appropriate for applications in urban flood assessment and mitigation using heterogeneous computing. Urban Water Journal 12(1), 67-78.

23. Sturm, M., Gems, B., Keller, F., Mazzorana, B., Fuchs, S., Papathoma-Köhle, M., Aufleger, M. (2018). Understanding the dynamics of impacts at buildings caused by fluviatile sediment transport processes. Geomorphology 321, 45-59.

24. Wang, L.-N., Chen, X.-H., Shao, Q.-X., Li, Y. (2015). Flood indicators and their clustering features in Wujiang River, South China. Ecological Engineering 76, 66-74.

25. Winterrath, T., Brendel, C., Hafer, M., Junghänel, T., Klameth, A., Lengfeld, K., Walawender, E., Weigl, E., and Becker, A. (2018). Radar-based precipitation climatology version 2017.002. Reprocessed quasi gauge-adjusted radar data, 5-minute precipitation sums (YW)

DOI:

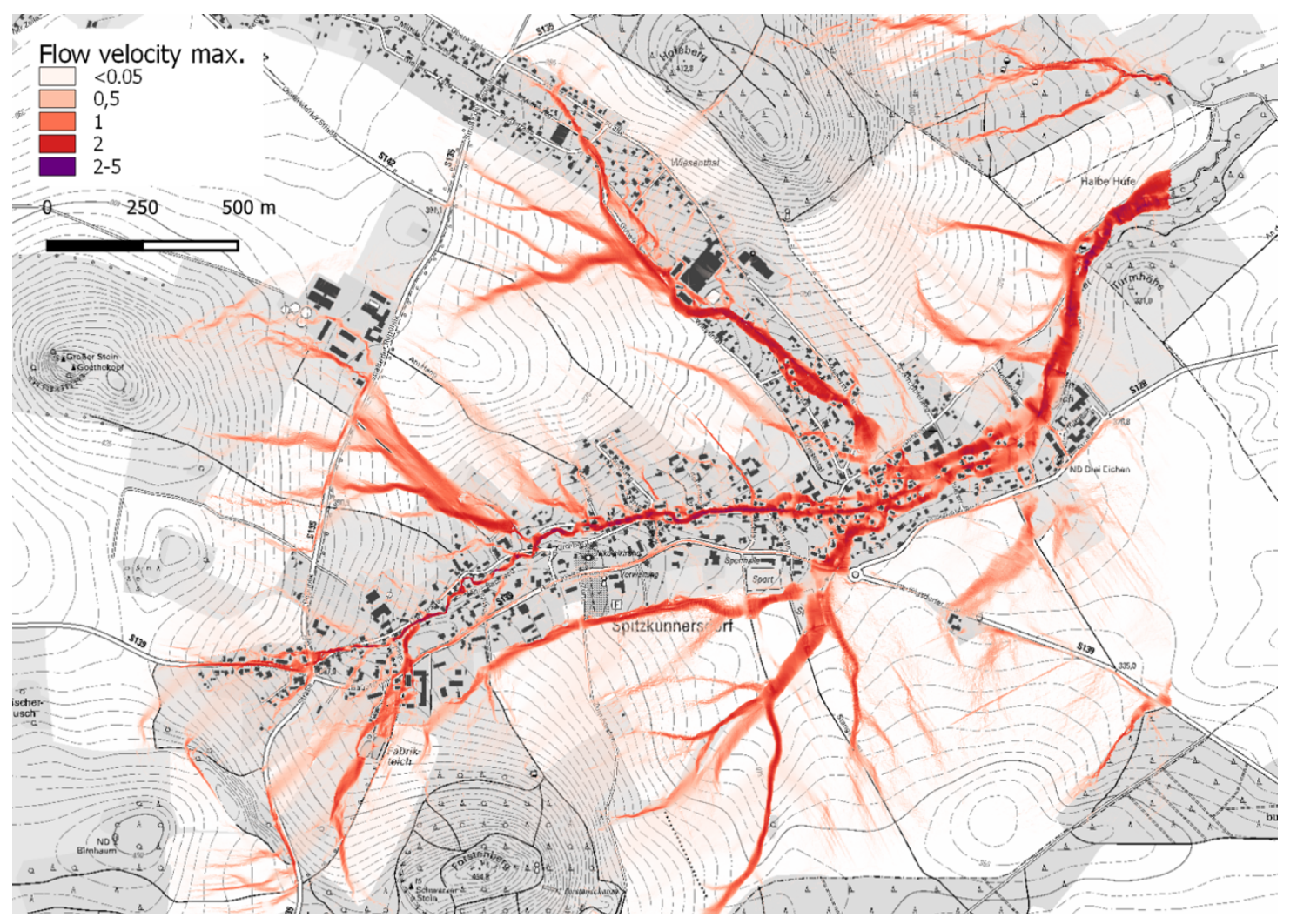

Figure 3. Map of the indicator $v_{f, \max }$ for the area SPK. The event is a $60 \mathrm{~min} 1: 100$ years synthetic EULER II storm (" 0.04 eu2_100" in Figure 2) ${ }^{\mathrm{b}}$.

b The background map is the official topographic map of GeoSN in the scale 1:10.000 with basic data about the location of receptors such as buildings and streets and with additional information on land use/vegetation and terrain (elevation isolines). 


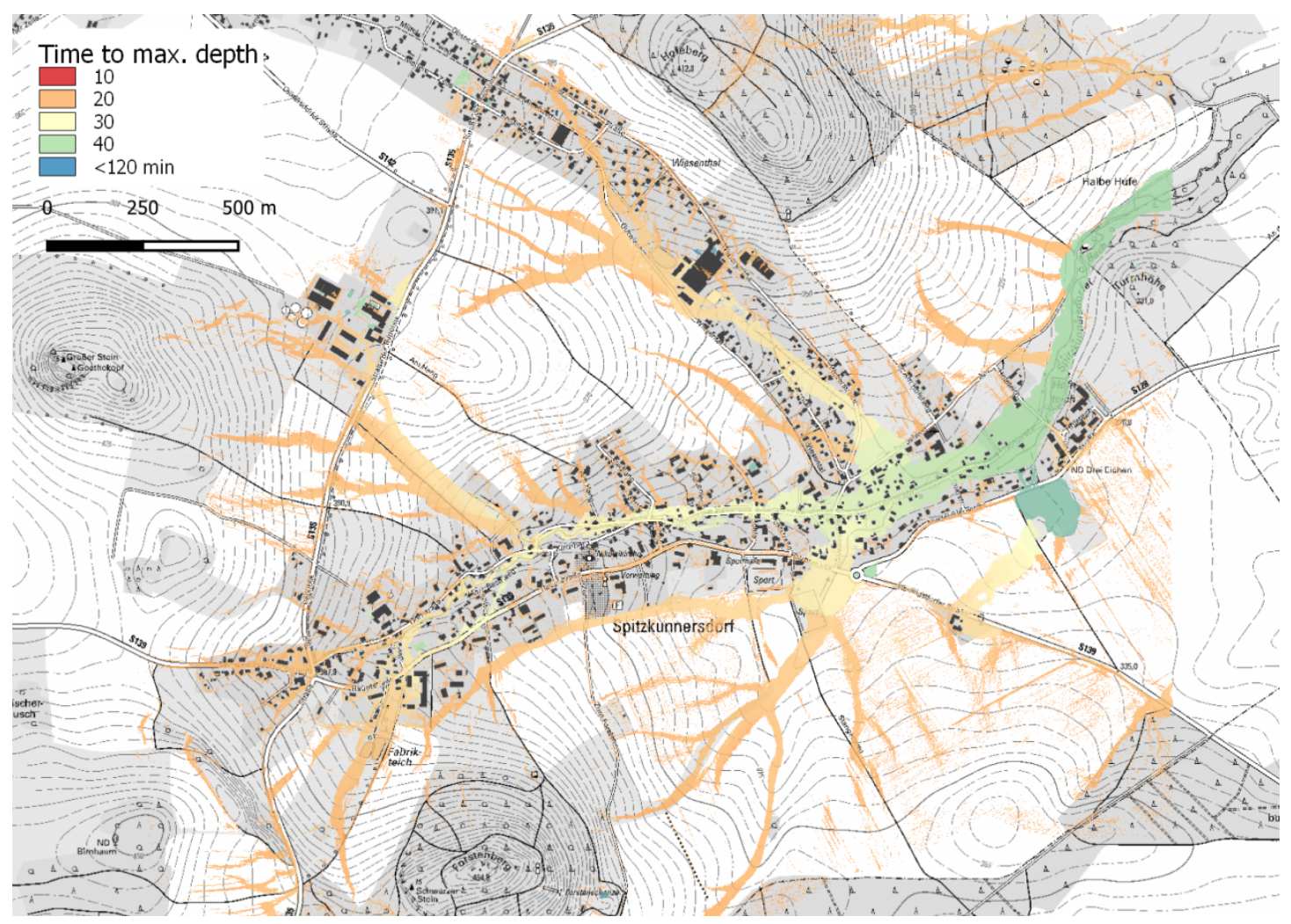

Figure 4. Map of the indicator $t_{h w, c r i t}\left(\right.$ here: $h_{w, \max }$ ) for the area SPK. The event is a 60 min 1:100 years synthetic EULER II storm ("0.04 eu2_100" in Figure 2).

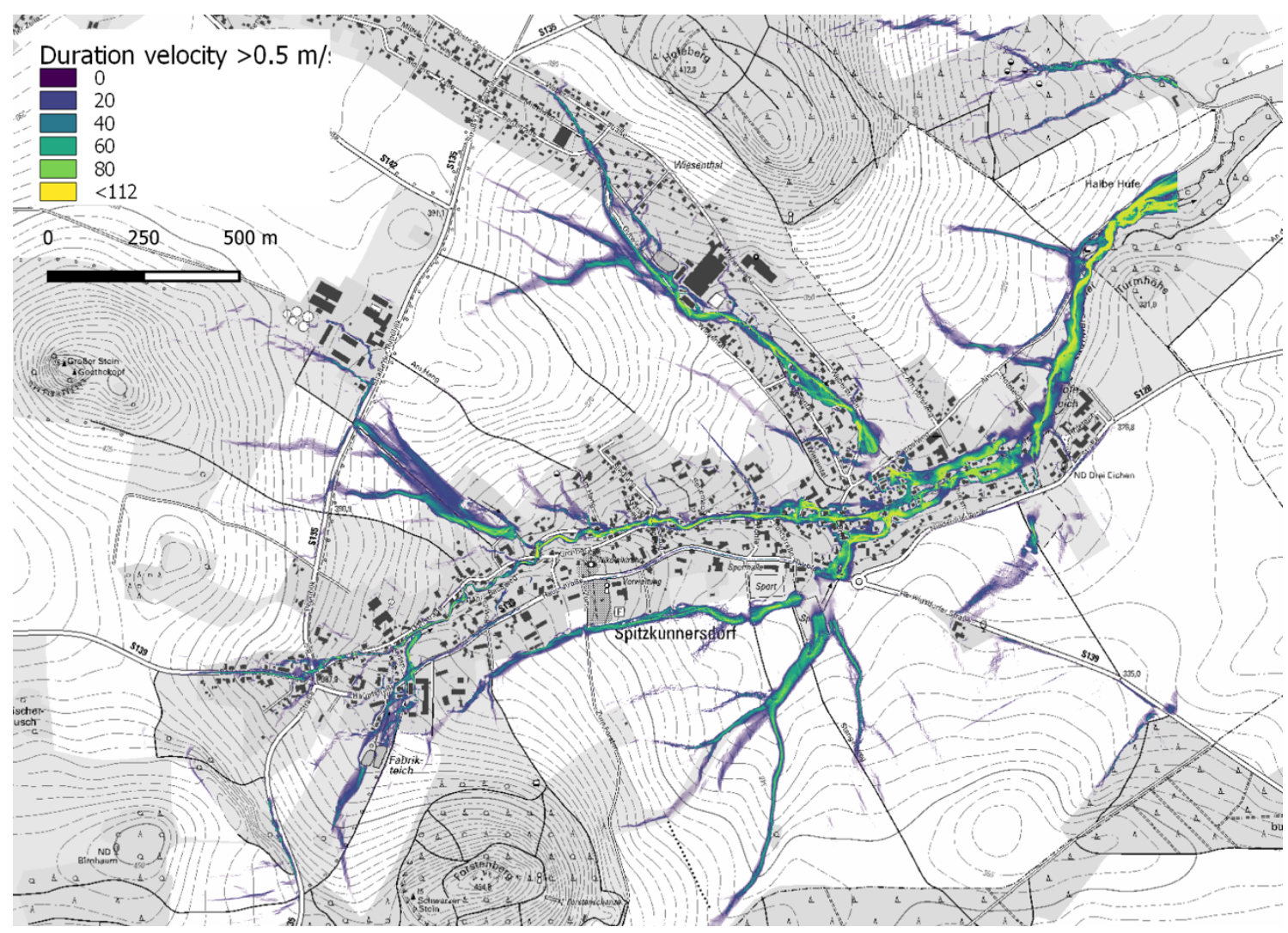

Figure 5. Map of the indicator $T_{v f, c r i t}$ (here: $>0.5 \mathrm{~m} / \mathrm{s}$ ) for the area SPK. The event is a 60 min 1:100 years synthetic EULER II storm ("0.04 eu2_100" in Figure 2) ${ }^{\text {b. }}$ 


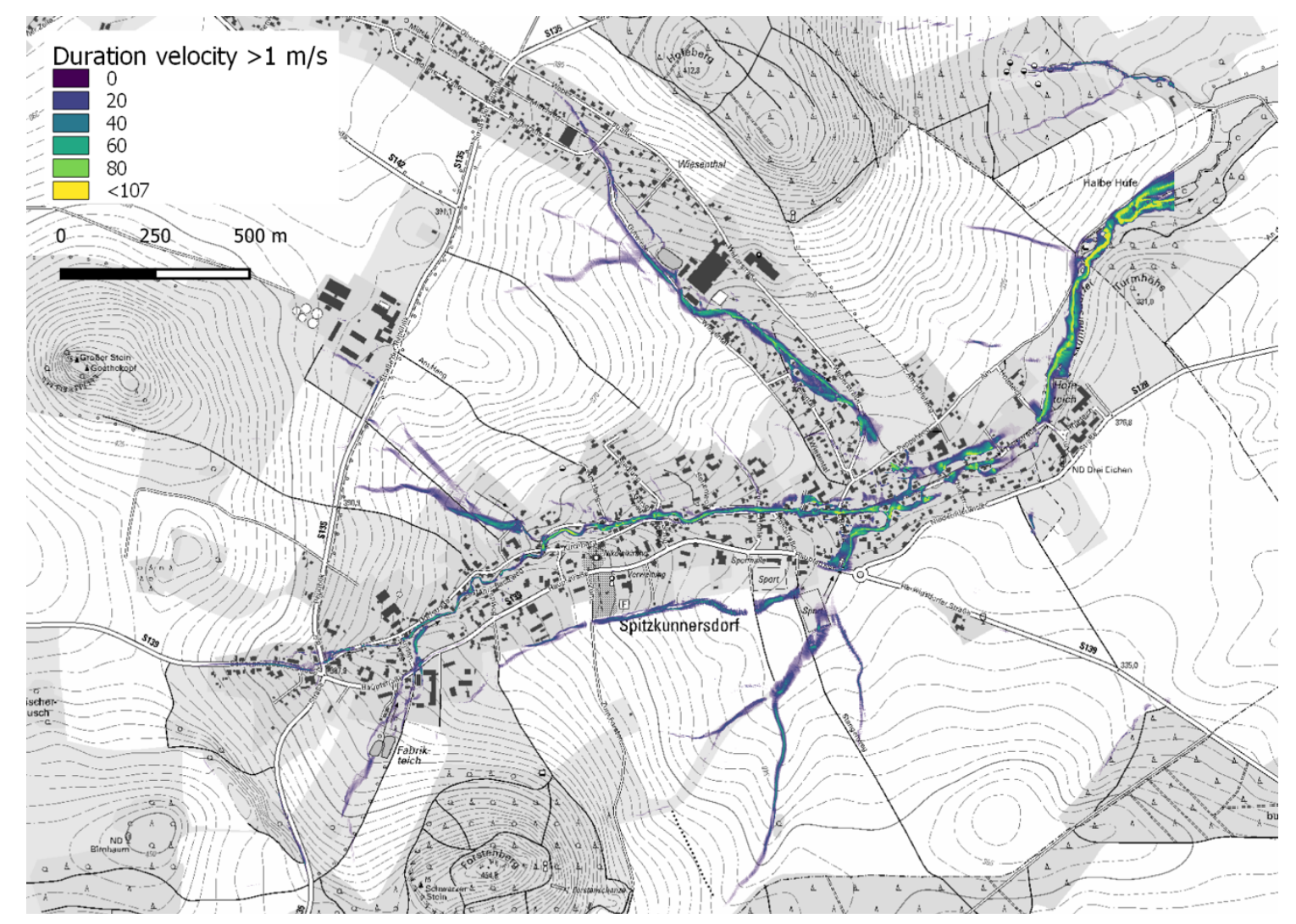

Figure 6. Map of the indicator $T_{v f, c r i t}$ (here: $>1 \mathrm{~m} / \mathrm{s}$ ) for the area SPK. The event is a $60 \mathrm{~min}$ 1:100 years synthetic EULER II storm (“0.04 eu2_100” in Figure 2) b.

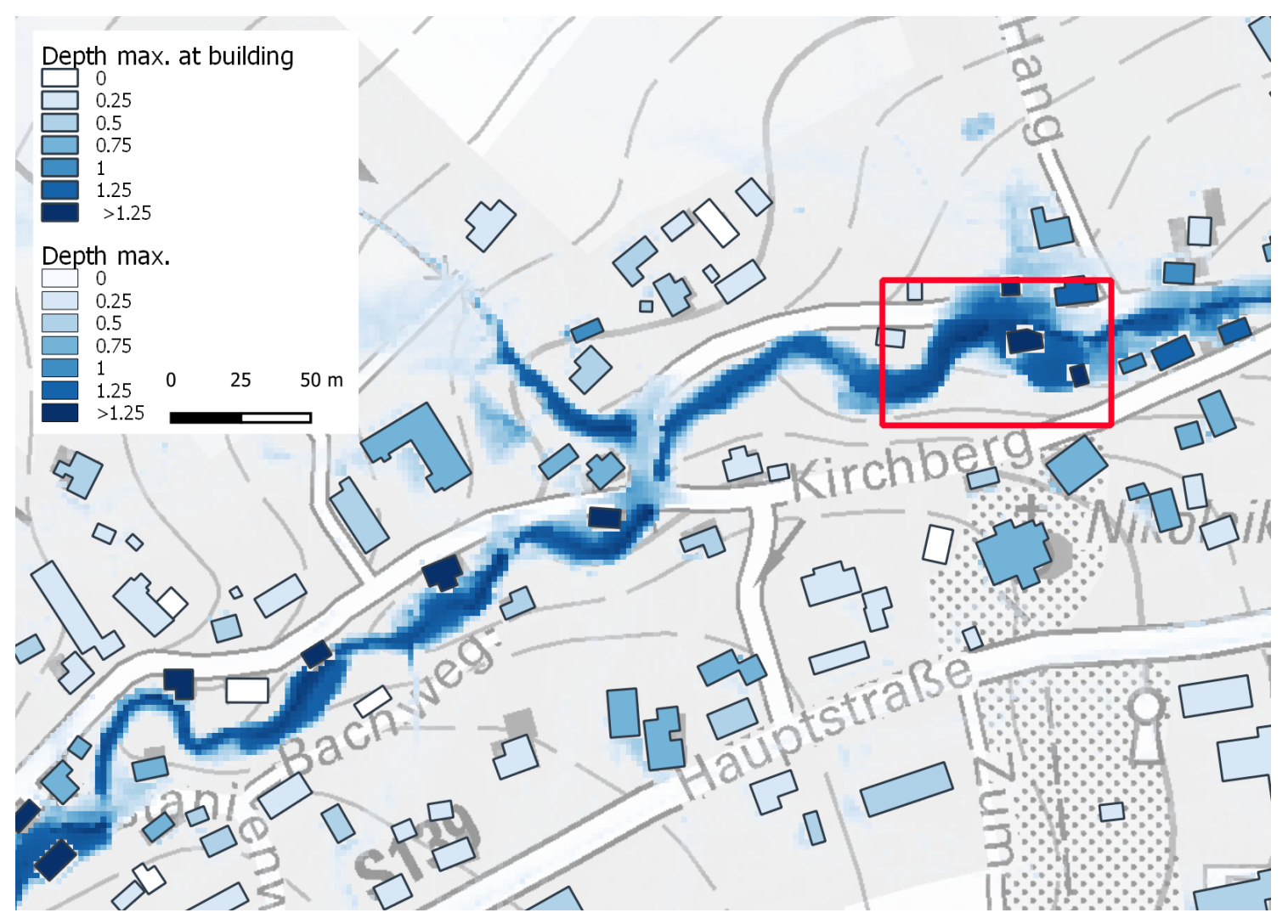

Figure 7. Map of the indicator $h_{w, \max }$ assigned to the receptor "buildings" for the area SPK. The event is a 60 min 1:100 years synthetic EULER II storm ("0.04 eu2 100" in Figure 2) ${ }^{\mathrm{b}}$. The area of the subset in Figure 1 is shown by the red box. 